\title{
Orchid Root Associated Bacteria: Linchpins or Accessories?
}

\author{
Jaspreet Kaur* and Jyotsna Sharma \\ Department of Plant and Soil Science, Texas Tech University, Lubbock, TX, United States
}

\section{OPEN ACCESS}

Edited by:

Christian Staehelin,

Sun Yat-sen University, China

Reviewed by:

Elena A. Dolgikh,

All-Russian Research Institute of Agricultural Microbiology of the

Russian Academy of Agricultural

Sciences, Russia

Chunlian Li,

Guangdong University of Technology,

China

*Correspondence: Jaspreet Kaur

Jaspreet.kaur@ttu.edu

Specialty section:

This article was submitted to

Plant Symbiotic Interactions, a section of the journal

Frontiers in Plant Science

Received: 31 January 2021 Accepted: 19 May 2021

Published: 24 June 2021

Citation:

Kaur J and Sharma J (2021) Orchid Root Associated Bacteria:

Linchpins or Accessories?

Front. Plant Sci. 12:661966.

doi: 10.3389/fp/s.2021.661966
Besides the plant-fungus symbiosis in arbuscular mycorrhizal (AM) and ectomycorrhizal (EM) plants, many endorhizal and rhizosphere bacteria (Root Associated Bacteria, or RAB) also enhance plant fitness, diversity, and coexistence among plants via bi- or tripartite interactions with plant hosts and mycorrhizal fungi. Assuming that bacterial associations are just as important for the obligate mycorrhizal plant family Orchidaceae, surprisingly little is known about the RAB associated with orchids. Herein, we first present the current, underwhelming state of RAB research including their interactions with fungi and the influence of holobionts on plant fitness. We then delineate the need for novel investigations specifically in orchid RAB ecology, and sketch out questions and hypotheses which, when addressed, will advance plant-microbial ecology. We specifically discuss the potential effects of beneficial RAB on orchids as: (1) Plant Growth Promoting Rhizobacteria (PGPR), (2) Mycorrhization Helper Bacteria (MHB), and (3) constituents of an orchid holobiont. We further posit that a hologenomic view should be considered as a framework for addressing co-evolution of the plant host, their obligate Orchid Mycorrhizal Fungi (OMF), and orchid RAB. We conclude by discussing implications of the suggested research for conservation of orchids, their microbial partners, and their collective habitats.

Keywords: mycorrhizal fungi, mycorrhization helper bacteria, orchids, plant growth promoting rhizobacteria, rhizosphere, roots

\section{INTRODUCTION}

Symbiotic association with bacteria is a fundamental condition in plants since their terrestrialization almost 400 mya. Nonetheless, we are just beginning to understand the functional mechanisms and the breadth of the ecological consequences of plant-microbial alliances (Martin et al., 2017). Among the bacterial communities that interact with plants, bacteria that colonize root compartments including the rhizosphere and intraradical regions (i.e., Root Associated Bacteria, or $\mathrm{RAB})$ can regulate the functioning of plant hosts (Box 1). Plants selectively recruit RAB in response to host genotype, metabolic profiles or root exudates and/or physicochemical properties of the soil (Bulgarelli et al., 2013). Many RAB are known to enhance plant growth through nutrient acquisition (Pii et al., 2015), hormonal provisions (Tsavkelova et al., 2016), protection from pathogens (Srivastava et al., 2016) and mitigation of abiotic stresses (Tiwari et al., 2016). Collectively, the RAB that confer growth benefits to plant hosts are termed as plant growth promoting rhizobacteria (PGPR), and generally belong to the bacterial phyla Proteobacteria, Actinobacteria, Firmicutes, and Bacteroidetes (Bulgarelli et al., 2013; Santoyo et al., 2016). Within these phyla, the genera Rhizobium, Bacillus, Pseudomonas, and Burkholderia feature prominently as PGPR, 
BOX 1 | Glossary of key terms.

Root Associated Bacteria (RAB)

Bacteria that colonize the rhizosphere and / or endorhizal spaces in a host plant.

Plant Growth Promoting Rhizobacteria (PGPR)

A subset of Root Associated Bacteria (RAB) that are specifically known to enhance plant growth.

\section{Mycorrhization Helper Bacteria (MHB)}

A group of Plant Growth Promoting Rhizobacteria (PGPR) that promote mycorrhizal colonization by improving spore germination,

hyphal and root branching, or by alleviating biotic and abiotic stresses. Orchid Mycorrhizal Fungi (OMF)

Fungi that establish mycorrhizal associations with orchids.

and some of their demonstrated functional contributions include mediating seed germination and subsequent plant growth (Glick, 2012; Kang et al., 2012; Walia et al., 2014). Though it is no longer questionable that symbiotic associations between roots and PGPR yield multiple growth benefits for the host plants, studies on the role of PGPR or other RAB in shaping plant ecology and evolution are scarce to non-existent (García Parisi et al., 2015; Siefert et al., 2019).

Emerging literature has shown variability in the community structure of RAB assemblages across plant taxa (Yeoh et al., 2017), seasons (He et al., 2020), and habitats (Mukhtar et al., 2018). This dynamic recruitment of RAB communities based on host phylogeny and microenvironment suggests their potential role in regulating broader ecological phenomena such as local adaptations and eco-evolutionary changes in plants. As such, rhizospheric microbiomes can impart novel traits to plants that consequently alter their ontogeny (Wagner et al., 2014; PankeBuisse et al., 2015; Lu et al., 2018). For instance, Panke-Buisse et al. (2015) showed that three genotypes of Arabidopsis thaliana and Brassica rapa exhibited delayed flowering and increased reproductive fitness when inoculated with the rhizosphere microbiome of a late-flowering ecotype of $A$. thaliana, and this study confirmed the differences in bacterial communities in the rhizosphere of early and late flowering genotypes of A. thaliana and B. rapa by $16 \mathrm{~S}$ rDNA sequencing. This provides some diffused evidence that by affecting the reproductive traits of plant hosts, RAB could ultimately shape their evolutionary trajectories. Ultimately, evolution is also directly influenced by reproductive barriers that steer divergence among species via reproductive isolation (Baack et al., 2015). Although geography and pollination syndromes are typically implicated in driving reproductive isolation in plants, symbiotic bacteria are known to cause reproductive isolation and speciation in insects by changing the mating preferences and hybrid lethality of their hosts (Sharon et al., 2010; Brucker and Bordenstein, 2013). Whether RAB can exert similar pressures on plant reproduction is currently unknown. Similarly, while covariation in host plant phylogeny and $\mathrm{RAB}$ community composition has been demonstrated in multiple studies (Peiffer et al., 2013; Bouffaud et al., 2014; Yeoh et al.,2017), the scientific community is yet to identify whether and how RAB assemblages propel plant phylogenesis and evolution.

While the magnitude of RAB effects on host ontogeny, phylogeny, and evolution remain poorly investigated, mechanisms of microbial influence on individual plants, their populations, and communities are slightly better studied and understood. Plants and microbes interact via a process described as plant soil feedbacks. As plants develop, they influence physical (soil temperature, moisture, and structure) and chemical properties (root cell lysates, $\mathrm{pH}$ and nutrients) of the soil surrounding them (Miki, 2012). This change in physicochemical properties causes shifts in the composition of rhizospheric bacterial and fungal communities (Miki, 2012; Krishna et al., 2020; Lin et al., 2020), which in turn alter the performance and fitness of the host. Microbe-mediated plant soil feedbacks range from positive to negative whereby either can promote species coexistence and community stabilization by affecting the fitness of key host taxa (Chung and Rudgers, 2016; Siefert et al., 2019). Negative plant soil feedbacks are generally attributed to the host-specific pathogens in soil, which often restrict the dominance of individual species in a community. In contrast, positive plant soil feedbacks reduce inter- or intraspecific competition for resources such as nutrients and soil moisture, fostering coexistence of diverse host taxa by precluding competitive exclusion. Along with promoting co-existence in plant communities, plant soil feedbacks are also known to steer community succession trajectories (Koziol and Bever, 2017; Wang et al., 2019; Zhang et al., 2020). For instance, a recent study showed that the soil fungal and bacterial communities conditioned by early successional plant species had positive effects on the mid successional species whereas soils conditioned by mid successional plant species exhibited negative effects on early successional species (Zhang et al., 2020). Interestingly, most of the plant soil feedbacks studies heretofore have focused either on Arbuscular Mycorrhizal Fungi (AMF) (Semchenko et al., 2018; Chen et al., 2019; Wang et al., 2019), or fungal pathogens (Hannula et al., 2020), whereas the stabilizing effects of PGPR, or other RAB, on plant communities largely remain neglected (Siefert et al., 2019). Such investigations are warranted for $\mathrm{RAB}$ to reveal their contributions, and possibly the coupled contributions of fungi and RAB, to plant community succession.

In fact, it is becoming increasingly evident that plant growth, diversity, and productivity is linked to tripartite interactions among plant hosts, PGPR, and mycorrhizal fungi (García Parisi et al., 2015; Van Der Heijden et al., 2016; Wang et al., 2016). For example, PGPR can interact with fungi to provision for plants by enhancing mycorrhizal associations. This group of PGPR is identified as Mycorrhization Helper Bacteria (MHB) that are known to stimulate expansion of mycelium, enhance lateral root formation, or modify host immunity to increase fungal infection (Bonfante and Anca, 2009; Kurth et al., 2013). Further, multiple studies have shown that $\mathrm{RAB}$ communities in $\mathrm{AM}$ and ectomycorrhizal (EcM) plant hosts are closely linked to the mycorrhizal communities (Singh et al., 2008; Vestergård et al., 2008; Bonfante and Anca, 2009; Nguyen and Bruns, 2015; Marupakula et al., 2016). Although it largely remains untested, non-random assemblies of RAB and mycorrhizal fungi in roots might be attributable to the variable specificities of RAB toward mycorrhizal fungi, or to the potential functioning of hosts, bacteria, and fungi as a unit, i.e., as a holobiont, that is putatively governed by a hologenome (Rosenberg and Zilber-Rosenberg, 2016). 
First introduced by Margulis (1991) to define a host and the entirety of its endosymbionts, the term holobiont now also includes exosymbionts (Rosenberg and Zilber-Rosenberg, 2018). Simultaneously, the more recently described concept of a hologenome, defined as the combined genomes of a host and its associated microbes, represents a paradigm shift in ecology and has rapidly become a topic of interest in a wide array of organisms (Rosenberg and Zilber-Rosenberg, 2016). The hologenome concept of evolution states that a holobiont with its hologenome is a distinct biological entity and an independent unit of selection for evolution (Rosenberg and Zilber-Rosenberg, 2016). The four tenets that form the basis of the hologenome concept include: (1) all organisms possess diverse microbiota (2) organisms, along with their microbes, function as distinct biological entities, (3) a microbiome is transmitted across generations, and (4) a change in microbiome structure contributes genetic variation to hologenomes (Rosenberg and Zilber-Rosenberg, 2016). These tenets also apply to plants given the diversity of microbes found in plant species and their ability to affect plant functions. Yet, hologenomic investigations in plant systems are exceedingly scarce (Hassani et al., 2018), which is increasingly seen as a compelling argument for our general inability to explain many of the complex ecological and evolutionary phenomena.

While considerations of RAB and hologenomes are generally in their infancy with respect to plant ecology and evolution, their functional contributions are almost entirely neglected in one of the largest and most evolutionarily advanced plant families, the Orchidaceae. This particular group of plants represents an excellent evolutionary model system with its high diversity of taxa and ecological strategies (including pollination and mycorrhizal dependencies), unique habits, habitats, and carbonacquisition modes across the estimated 30,000 species, and pan-global distribution. All members of the orchid family are considered rare and are afforded protection at local, regional, national, and international scales (Fay, 2018). One of the distinctive ecological requirements in all orchids is their dependence on mycorrhizal fungi that are known as Orchid Mycorrhizal Fungi (OMF) during germination and development of the rudimentary embryos. Besides, the orchidOMF associations continue as partial or full dependence in later life stages of an orchid species depending on its photosynthetic capacity. Owing to this mycorrhizal requirement, taxonomic specificity and interactions of orchids and their OMF are generally well studied by now. Curiously though, the roles of $\mathrm{RAB}$, particularly $\mathrm{MHB}$, in orchid ecology have not been considered in an appreciable manner. Considering the emerging recognition of functional contributions of RAB to plant performance and evolution in other systems, it is conceivable that RAB, holobiomes, and hologenomes hold a significant unexplored potential for orchids (Figure 1). Especially considering that in a number of cases where OMF and microenvironment, either individually or together, fail to explain orchid distributions or fitness, a consideration of RAB together with OMF, environment, and holobiomes/hologenomes might allow scientists and practitioners to explain ecological and evolutionary processes in one of the largest and most distinct plant families on earth. In this review, we first present and discuss the current knowledge of orchid RAB and then present potential testable hypotheses that, when tested, will advance plant microbial ecology. The proposed conceptual models will especially inform the understanding of symbiotic interactions in one of the largest, most at-risk, and biologically complex plant families on earth.

\section{THE CONSPICUOUSLY LIMITED KNOWLEDGE OF ORCHID RAB AND THEIR FUNCTIONS}

The first reports of culture-based isolations of bacteria from orchid root systems are from Australian terrestrial orchids (Wilkinson et al., 1989, 1994). Based on the fatty acid analyses, these isolates primarily belonged to the genera Pseudomonas, Xanthomonas, Arthrobacter, and Bacillus (Table 1). Similarly, based on various morphological, biochemical and / or molecular analyses, orchid RAB isolates belonging to the genera Mycobacterium, Arthrobacter, Bacillus, Pseudomonas, and Rhodococcus were identified from roots of epiphytic and terrestrial orchids in Russia (Tsavkelova et al., 2001, 2004, 2007a; Table 1). Subsequently, a study by Júnior et al. (2011) isolated bacterial strains from roots of a tropical orchid Cattleya walkeriana, which belonged to genera Bacillus, Pseudomonas, Enterobacter, and Burkholderia based on $16 \mathrm{~S}$ rDNA sequencing. More recently, multiple studies have repeatedly reported orchid $\mathrm{RAB}$ belonging to the genera Pseudomonas, Enterobacter, Sphingomonas, and Bacillus from orchids in China and South America (Yang et al., 2014; Wang et al., 2016; Herrera et al., 2020).

Reports of orchid RAB based on culture-independent methods are scarcer still (Table 1). Only five such studies are available, of which two utilized Sanger sequencing (Yu et al., 2013; Novotná and Suárez, 2018) and the other three utilized high throughput sequencing to sequence the $16 \mathrm{~S}$ rDNA barcoding region of bacterial communities directly from root or OMF DNAs (Li et al., 2017; Alibrandi et al., 2020; Lin et al., 2020). The study by Yu et al. (2013) amplified endophytic bacteria belonging to Burkholderia, Rhodanobacter, Pseudomonas and Sphingomonas from the roots of Dendrobium officinale while Novotná and Suárez (2018) identified several bacterial strains representing genera Bacillus, Streptococcus, and Acidobacter associated with an orchid mycorrhizal fungus [a Serendipita sp.] of a tropical epiphytic orchid Stanhopea connata. On the other hand, Li et al. (2017) reported taxa within Pseudomonas, Shigella, Delftia, Burkholderia, Sphingomonas, and Pantoea dominating the endophytic bacterial communities in roots of an epiphytic orchid Dendrobium catenatum in China while Alibrandi et al. (2020) reported Cutibacterium, Luteibacter, and Corynebacterium as the dominant taxa from three terrestrial orchids of Italy. The third report utilizing high throughput sequencing documented the dominance of endophytic bacterial families Comamonadaceae, Chitinophagaceae, Cytophagaceae, and Sphingobacteriaceae in roots of an Asian orchid Gymnadenia conopsea (Lin et al., 2020). 


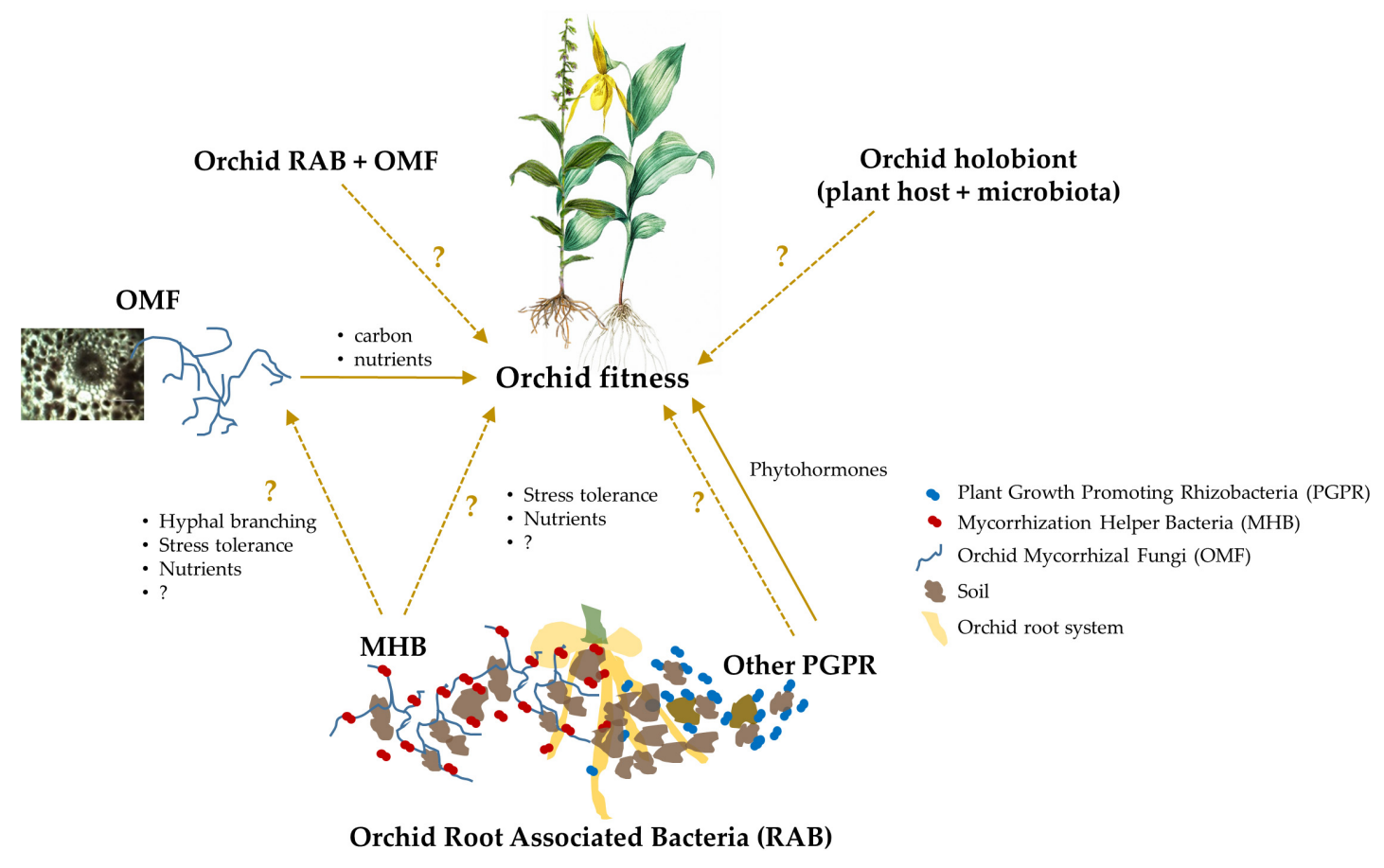

FIGURE 1 | A schematic representation of the known and putative effects of orchid Root Associated Bacteria (RAB) on plant fitness, which eventually governs species ecology and evolution. Some orchid RAB are known to enhance plant fitness as Plant Growth Promoting Rhizobacteria (PGPR), and although currently unknown, they also may confer beneficial effects by helping Orchid Mycorrhizal Fungi (OMF) as Mycorrhization Helper Bacteria (MHB). The coupling of orchid RAB and OMF, and a combination of the host orchid and its microbiota (i.e., the orchid holobiont) likely also influence plant fitness, but these mechanisms are currently unknown in orchids. In the schematic, the unknown or underexplored interactions or effects are represented with dashed arrows and questions marks, while the known effects are represented with solid arrows.

We have provided a complete list of bacteria isolated from orchid root systems in Table 1. Interestingly, orchid RAB reported so far show a remarkable overlap with bacteria commonly known as PGPR, or more specifically as MHB (Frey-Klett et al., 2007; Glick, 2012). This trend suggests that orchid RAB likely exert similar, and other as yet unknown, influences on orchids (Figure 1). We discuss below the few known, and the many potential, but yet untested, pathways through which orchid RAB can underpin orchid ecology and evolution but remain obscure. Toward this end, we first present the known roles of RAB in plant fitness and then use this information to provide similar and novel perspectives on the role of orchid RAB in orchid ecology.

\section{FUNCTIONAL ROLES OF RAB IN PLANT BIOLOGY AND PERSPECTIVES ON THE ROLE OF ORCHID RAB IN ORCHID NICHES}

\section{RAB as PGPR}

\section{Abiotic and Biotic Stress Alleviation by Acting as Bio-Ameliorators}

Plant cells perceive abiotic stresses such as freezing temperatures through the production of Reactive Oxygen Species (ROS) and calcium spiking in cytosol whereby high levels of
ROS degrade nucleic acids, proteins and lipids, leading to physical damage of plant cells (Liu et al., 2017). RAB are known to mediate abiotic stress tolerance in plants by modulating the production of ROS. For instance, endophytic Pseudomonas strains conferred cold resistance in tomato plants through production of antioxidant enzymes that maintain ROS homeostasis in cytosol (Ding et al., 2011; Subramanian et al., 2015). Similarly, a study by Sheibani-Tezerji et al. (2015) showed that an endophytic Burkholderia strain was able to sense the drought stress and change its own transcriptome profile to upregulate genes associated with maintaining cellular homeostasis to destroy excessive ROS, resulting in improved plant performance under drought stress. Beneficial RAB also alleviate plant biotic stresses either directly or indirectly (Liu et al., 2017). Direct beneficial effects may be exerted by producing allelochemicals such as antibiotics, hydrogen cyanide, iron chelating siderophores or volatile organic compounds to increase resistance to plant pathogens and pests (Liu et al., 2017). Alternatively, RAB may also inhibit pathogens through the quenching mechanism that destroys the quorum sensing signals in pathogenic microorganisms (Kusari et al., 2014). Besides, endophytic RAB can inhibit pathogens indirectly by inducing systemic resistance in plants through jasmonic acid, salicylic acid, or ethylene dependent pathways and consequently priming plants for more intense defense responses (Brock et al., 2013; Glaeser et al., 2016). 
TABLE 1 | A summary of the genera or families of orchid Root Associated Bacteria (RAB) identified either by culture-dependent or culture-independent methods.

\begin{tabular}{|c|c|c|c|c|}
\hline Reference & Orchid taxon & Country & Source & Orchid RAB identity \\
\hline \multicolumn{5}{|c|}{ Culture-dependent studies } \\
\hline \multirow{12}{*}{$\begin{array}{l}\text { Wilkinson et al., 1989, } \\
1994\end{array}$} & Caladenia latifolia & Australia & Root endophytes & Pseudomonas ${ }^{\dagger}$ \\
\hline & Diurnis longifolia & Australia & Root endophytes & $\begin{array}{l}\text { Pseudomonas, Cedecea }{ }^{\ddagger}, \text { Salmonella, Bacillus }{ }^{\dagger}, \text { Arthrobacter }^{\dagger}, \text { Kurthia }^{\ddagger}, \\
\text { Micrococcus }\end{array}$ \\
\hline & Diurnis purdiei & Australia & Root endophytes & Pseudomonas, Bacillus \\
\hline & Eriochilus dilatatus & Australia & Root endophytes & Bacillus, Kurthia, Micrococcus, Staphylococcus ${ }^{\ddagger}$ \\
\hline & Leporella fimbriata & Australia & Root endophytes & Pseudomonas, Bacillus, Arthrobacter, Kurthia \\
\hline & Lyperanthus nigricans & Australia & Root endophytes & Pseudomonas, Bacillus, Arthrobacter, Kurthia \\
\hline & Pterostylis recurva & Australia & Root endophytes & Pseudomonas, Xanthomonas, Morganella ${ }^{\ddagger}$, Acinetobacter, Bacillus, Kurthia \\
\hline & Pterostylis vittata & Australia & Root endophytes & Pseudomonas, Erwinia ${ }^{\ddagger}$, Bacillus, Kurthia \\
\hline & $\begin{array}{l}\text { Rhizanthella } \\
\text { gardneri }\end{array}$ & Australia & Root endophytes & Pseudomonas, Yersinia \\
\hline & Spiculaea ciliata & Australia & Root endophytes & Pseudomonas \\
\hline & Thelymitra crinita & Australia & Root endophytes & Pseudomonas, Bacillus, Arthrobacter, Kurthia \\
\hline & $\begin{array}{l}\text { Thelymitra } \\
\text { fuscolutea }\end{array}$ & Australia & Root endophytes & Xanthomonas ${ }^{\dagger}$, Kurthia, Staphylococcus \\
\hline \multirow[t]{2}{*}{ Tsavkelova et al., 2001} & $\begin{array}{l}\text { Calanthe vestita } \\
\text { var. rubrooculata }\end{array}$ & Russia & Rhizoplane & Pseudomonas, Bacillus, Mycobacterium ${ }^{\dagger}$, Arthrobacter \\
\hline & $\begin{array}{l}\text { Dendrobium } \\
\text { moschatum }\end{array}$ & Russia & Rhizoplane & $\begin{array}{l}\text { Pseudomonas, Bacillus, Curtobacterium }{ }^{\ddagger}, \text { Flavobacterium }^{\ddagger}, \text { Nocardia }^{\ddagger} \text {, } \\
\text { Rhodococcus }{ }^{\ddagger} \text {, Xanthomonas }\end{array}$ \\
\hline \multirow[t]{3}{*}{ Tsavkelova et al., 2004} & Acampe papillosa & Russia & Rhizoplane & $\begin{array}{l}\text { Pseudomonas, Bacillus, Flavobacterium, Rhodococcus, Micrococcus, } \\
\text { Streptomyces }{ }^{\ddagger} \text {, Cellulomonas }{ }^{\ddagger} \text {, Xanthomonas, Acinetobacter, Gluconobacter, } \\
\text { Mycobacterium }\end{array}$ \\
\hline & Acampe papillosa & Russia & Endorhizal & Pseudomonas, Bacillus, Flavobacterium, Rhodococcus, Xanthomonas \\
\hline & $\begin{array}{l}\text { Dendrobium } \\
\text { moschatum }\end{array}$ & Russia & Rhizoplane & Pseudomonas, Bacillus, Acinetobacter, Aquaspirillum, Rhodococcus \\
\hline \multirow[t]{4}{*}{$\begin{array}{l}\text { Tsavkelova et al., } \\
2007 \text { a }\end{array}$} & $\begin{array}{l}\text { Paphiopedilum } \\
\text { appletonianum }\end{array}$ & Vietnam & Rhizoplane & Pseudomonas, Bacillus, Burkholderia ${ }^{\ddagger}$, Streptomyces, Erwinia, Nocardia \\
\hline & $\begin{array}{l}\text { Paphiopedilum } \\
\text { appletonianum }\end{array}$ & Vietnam & Endorhizal & Pseudomonas, Bacillus, Streptomyces, Erwinia \\
\hline & Pholidota articulata & Vietnam & Rhizoplane & $\begin{array}{l}\text { Pseudomonas, Bacillus, Burkholderia, Erwinia, Flavobacterium, } \\
\text { Stenotrophomonas }{ }^{\dagger}, \text { Pantoea }^{\ddagger}, \text { Chryseobacterium } \\
\\
\text { Paracoccus }^{\ddagger}\end{array}$ \\
\hline & Pholidota articulata & Vietnam & Endorhizal & Pseudomonas, Bacillus, Flavobacterium \\
\hline \multirow[t]{2}{*}{ Júnior et al., 2011} & Cattleya walkeriana & Brazil & Rhizoplane & $\begin{array}{l}\text { Pseudomonas, Bacillus, Burkholderia, Pantoea, Curobacterium, Enterobacter }{ }^{\dagger} \text {, } \\
\text { Achromobacter }{ }^{\ddagger}\end{array}$ \\
\hline & Cattleya walkeriana & Brazil & Endorhizal & Pseudomonas, Bacillus, Burkholderia, Pantoea, Curobacterium, Enterobacter \\
\hline Yang et al., 2014 & $\begin{array}{l}\text { Dendrobium } \\
\text { officinale }\end{array}$ & China & Endorhizal & Sphingomonas ${ }^{\dagger}$ \\
\hline Wang et al., 2016 & $\begin{array}{l}\text { Dendrobium } \\
\text { catenatum }\end{array}$ & China & Endorhizal & Enterobacter, Herbaspirillum ${ }^{\dagger}$ \\
\hline Gontijo et al., 2018 & Cymbidium sp. & Brazil & Endorhizal & Pseudomonas, Bacillus, Herbaspirillum, Rhizobium ${ }^{\dagger}$, Stenotrophomonas \\
\hline \multirow[t]{6}{*}{ Herrera et al., 2020} & Chloraea barbata & Chile & Endorhizal & Pseudomonas \\
\hline & Chloraea collicensis & Chile & Endorhizal & Bacillus, Exiguobacterium ${ }^{\ddagger}$, Dyella, Luteibacter ${ }^{\ddagger}$ \\
\hline & Chloraea gavilu & Chile & Endorhizal & Pandoraea ${ }^{\ddagger}$ \\
\hline & Chloraea magellanica & Chile & Endorhizal & Pseudomonas, Collimonas ${ }^{\ddagger}$, Chryseobacterium \\
\hline & Gavilea araucana & Chile & Endorhizal & Pseudomonas \\
\hline & Gavilea lutea & Chile & Endorhizal & Pseudomonas \\
\hline \multicolumn{5}{|c|}{ Culture-independent studies } \\
\hline Yu et al., 2013 & $\begin{array}{l}\text { Dendrobium } \\
\text { officinale }\end{array}$ & China & Endorhizal & Burkholderia, Rhodanobacter ${ }^{\ddagger}$, Pseudomonas, Sphingomonas \\
\hline Li et al., 2017 & $\begin{array}{l}\text { Dendrobium } \\
\text { catenatum }\end{array}$ & China & Endorhizal & $\begin{array}{l}{ }^{*} \text { Pseudomonas, Delftia }{ }^{\ddagger} \text {, Shigella, Burkholderia, Pantoea, Sphingomonas, } \\
\text { Buttiauxella }{ }^{\ddagger}, \text { Duganella }{ }^{\ddagger} \text {, Acinetobacter }{ }^{\ddagger} \text {, Pectobacterium }\end{array}$ \\
\hline $\begin{array}{l}\text { Novotná and Suárez, } \\
2018\end{array}$ & Stanhopea connata & Ecuador & $\begin{array}{l}\text { Bacteria associated with } \\
\text { OMF }\end{array}$ & Bacillus, Gemella, Staphylococcus, Streptococcus, Paracoccus, Achromobacter \\
\hline \multirow[t]{3}{*}{ Alibrandi et al., 2020} & Neottia ovata & Italy & Endorhizal & ${ }^{*}$ Cutibacterium, Rhodanobacter, Dolosigranulum, Corynebacterium \\
\hline & Serapias vomarecea & Italy & Endorhizal & ${ }^{*}$ Cutibacterium, Corynebacterium, Pseudomonas, Luteibacter \\
\hline & Spiranthes spiralis & Italy & Endorhizal & ${ }^{*}$ Mycobacterium, Candidatus Ovatusbacter \\
\hline \multirow[t]{2}{*}{ Lin et al., 2020} & Gymnadenia & China & Endorhizal & $\begin{array}{l}\text { *Comamonadaceae, Chitinophagaceae, Sphingobacteriaceae, Cytophagaceae, } \\
\text { Rhizobaceae, Acidobacteriaceae }\end{array}$ \\
\hline & conopsec & & & \\
\hline
\end{tabular}

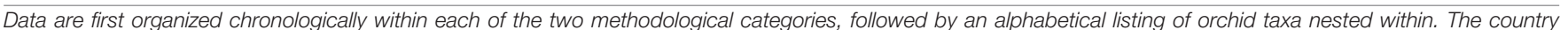

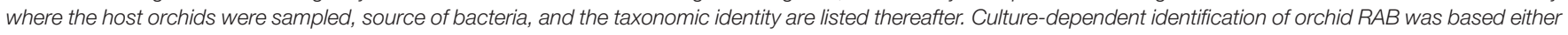

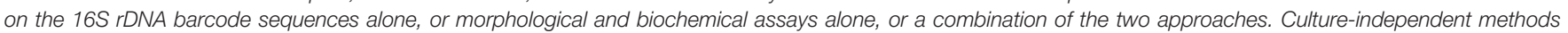

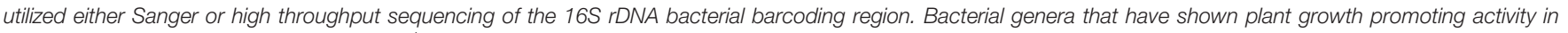

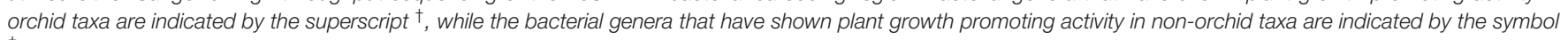

‡. *Only the dominant bacterial taxa that showed high relative abundances are listed here. 


\section{Production of 1-Aminocyclopropane-1-Carboxylate (ACC) Deaminase}

Biotic and abiotic stresses induce ethylene production in plants, which limits plant growth and enhances cell death at high concentrations (Afzal et al., 2019). Under stressful conditions, plants produce ACC (an immediate precursor to ethylene) in roots, from where it is transported to shoots and gets converted to ethylene in leaves (Liu et al., 2017). Beneficial RAB sequester ACC in roots, hydrolyze it by producing ACC deaminase and then use the byproducts as nitrogen and carbon sources (Sun et al., 2009; Glick, 2014), leading to lower ethylene levels and enhanced plant growth under stressed conditions. This effect was shown by Qin et al. (2014) when root endophytic bacteria capable of producing ACC-deaminase enhanced seed germination and plant growth in a halophyte host Limonium sinense under salt stress.

\section{Production of Phytohormones}

Genomes of RAB often possess genes encoding for proteins involved in the biosynthesis of phytohormones such as indole acetic acid (Zhang et al., 2019) and gibberellins (Nett et al., 2020). Indeed, multiple studies have corroborated the production of phytohormones in RAB (Tsavkelova et al., 2007a; Hoffman et al., 2013; Toumatia et al., 2016) and their growth enhancing effects in plants. A large body of literature has illustrated the role of bacterial indole acetic acid in increasing root biomass, surface area, and lateral branching (Patten and Glick, 2002; Tsavkelova et al., 2007a). Gibberellins produced by RAB has been shown to enhance shoot growth and chlorophyll content under abiotic stresses (Kang et al., 2014; Khan et al., 2014), and similarly RAB cytokinins improve root and shoot biomass under stressed conditions (Arkhipova et al., 2005; Liu et al., 2013).

\section{Nutrient Acquisition}

Nutritional provisioning by increasing the availability of nitrogen, iron and phosphorus is another way some RAB can directly promote plant growth. These elements are key components of proteins, enzymes, and other cellular compounds that drive plant physiological processes such as transpiration and respiration. Often, they are present in organic or inorganic insoluble forms that cannot be utilized by plants, and RAB can mediate their uptake. For example, RAB support the uptake of iron by producing siderophores or chelating agents that bind to the insoluble ferric ions in soil. Plants then acquire iron from bacterial siderophores through root-mediated degradation of siderophores (Rajkumar et al., 2009). Likewise, some beneficial $\mathrm{RAB}$ improve the availability of phosphorus by solubilizing phosphorus through acidification, chelation, or by releasing phosphatases. Besides, RAB also enhance the availability of nitrogen to plants by fixing atmospheric nitrogen through nitrogenase activity. In fact, along with the well-known legumeRhizobium symbioses for nitrogen fixation, bacteria within the genera Azospirillum, Burkholderia, Gluconacetobacter, and Paenibacillus also fix atmospheric nitrogen and enhance plant biomass under nitrogen limited environments (Scherling et al., 2009; Gupta et al., 2013; Afzal et al., 2019).

Apart from promoting the growth of individual plants, PGPR are also known to enhance coexistence among plant species and thus stabilize community structures via plant soil feedback mechanisms. For instance, Siefert et al. (2019) have shown the stabilization effects of PGPR (Rhizobium sp.) in experimental communities where four Trifolium species were sown together at variable relative frequencies and inoculated with strains of Rhizobium isolated either from conspecific or congeneric plant hosts. The results showed that inoculation with strains from conspecific hosts reduced the fitness of Trifolium taxa in a frequency-dependent manner, indicating that species-specific mutualists provide negative plant soil feedback to impose self-limitation on hosts, resulting in stabilization of plant communities. In another study, Van Der Heijden et al. (2016) established gnotobiotic microcosms simulating European grasslands and demonstrated that co-inoculations of Rhizobium strains and mycorrhizal fungi resulted in higher plant diversity, seedling recruitment and enhanced nutrient uptake in comparison to single symbiont inoculations. This study suggested that bacteria and mycorrhizal fungi complement each other in enhancing community diversity and productivity.

\section{Orchid RAB as PGPR}

Explaining many aspects of orchid ecology and evolution including patterns of seed germination, vegetative dormancies (i.e., absence of plant emergence or aboveground growth from perennating structures) in geophytes, or species distributions, however, has always been an enigmatic task, especially when mycorrhizal fungi and/or abiotic environment have not been entirely successful in predicting the triggers and outcomes of these processes (McCormick et al., 2016; Calevo et al., 2020). Considering the growth enhancing roles of beneficial RAB, it is highly likely that orchid $\mathrm{RAB}$ include beneficial bacteria that facilitate plant growth, fitness, and a number of other ecological or evolutionary processes in orchids (Figure 1). For instance, McCormick et al. (2016) reported a lack of orchid seed germination at locations away from conspecific plants even though the species-specific OMF was present, while germination was higher at locations near conspecific plants in the presence of OMF. These observations convincingly reveal that factors other than OMF steer orchid seed germination. As such, it is possible that the growth promoting activity of orchid RAB could be contributing to the variation in seed germination responses, and hence plant distributions, in situ.

In fact, the limited amount of literature available on orchid $\mathrm{RAB}$ suggests that orchid $\mathrm{RAB}$ can supplement orchid niches through phytohormone production, nutritional support, or by enhancing stress tolerance. The potential of several orchid RAB to produce indole acetic acid and improve seed germination and plant growth has been demonstrated by several researchers (Wilkinson et al., 1989, 1994; Tsavkelova et al., 2007b, 2016; Júnior et al., 2011; Yang et al., 2014) and hypothesized to occur in vivo (Teixeira da Silva et al., 2015). For example, bacterial isolates from roots of multiple orchid taxa produced indole acetic acid and enhanced mycorrhiza-assisted germination of Pterostylis vittata seeds (Wilkinson et al., 1989, 1994). In another study, Tsavkelova et al. (2007b) showed that bacteria isolated from the rhizoplane of Dendrobium moschatum produced indole acetic acid and promoted asymbiotic seed germination. More recently, 
Júnior et al. (2011) showed that endophytic and rhizoplane bacteria isolated from Cattleya walkeriana produced indole acetic acid and promoted the growth of asymbiotically germinated seedlings of C. walkeriana under greenhouse conditions. Overall though, besides a handful of studies focused on phytohormone production, other possible orchid RAB-mediated growth effects remain largely unknown in orchids. To our knowledge, only one study has reported the potential of orchid RAB to support the nutritional niche of orchids and to provide biotic stress tolerance (Yang et al., 2014). Therein, an endophytic bacterium Sphingomonas paucimobilis, isolated from the roots of Dendrobium officinale exhibited the capacity to fix atmospheric nitrogen, and increased seedling growth and biomass; although, a direct relationship between nitrogen fixation and seedling growth was not presented. Nonetheless, orchid RAB-mediated nutrient uptake is a plausible scenario in orchids especially within the context of their nutritional dependencies during seed germination and in subsequent life stages. Further, Yang et al. (2014) also reported that seedlings inoculated with S. paucimobilis showed high concentration of salicylic acid, indole acetic acid, and abscisic acid, which possibly promote growth or provide systemic resistance against biotic stresses to the host orchid as seen in other plants.

Beyond enhancing plant growth, another intriguing functional possibility is the orchid RAB-mediated regulation of vegetative dormancy in geophytic orchids. Whether such dormancies are an adaptive or a bet-hedging trait remains unknown (Shefferson et al., 2020), though they are believed to be triggered by stresses such as drought and herbivory (Shefferson et al., 2018). Abiotic and biotic stresses may cause orchid dormancy within or across growing seasons within an individual plant when resource accumulation in perennating structures is insufficient to support emergence (Shefferson et al., 2018) even when the stresses dissipate. Within this context, it is reasonable to hypothesize that orchid RAB might prevent the onset of dormancy via at least two mechanisms: (1) by providing nutritional and hormonal support to improve carbon accumulation, and/or (2) by secreting ACC deaminase and gibberellins to counteract the activity of the stress hormones ethylene and abscisic acid. Further, it is possible that orchids derive such benefits by utilizing a synergistic coupling of orchid $\mathrm{RAB}$ and OMF; hence, their combined contributions to orchid fitness merit just as much attention.

\section{RAB as MHB}

While orchid RAB may directly influence orchid fitness, it is equally plausible that complementation or synergies between orchid RAB and OMF mediate the fitness of their hosts, thereby directing the fate of individuals, their populations, and the species. The concept of mycorrhization helper bacteria (MHB) was first discussed by Garbaye (1994) who defined $\mathrm{MHB}$ as the bacteria that promote formation of mycorrhizae. As such, MHB can be considered a subset of PGPR that may reside intimately with mycorrhizal fungi in the hyphosphere, mycorrhizosphere, or sporocarps or in other environments like plant endosphere, rhizosphere, and soil that are not directly related to fungal tissues (Deveau and Labbé, 2017). In fact, $\mathrm{MHB}$ are implicated in improving mycorrhizal colonization by enhancing spore germination, mycelial extension and by increasing the receptivity of roots to fungi by increasing root surface area (Frey-Klett et al., 2007). For example, Labbé et al. (2014) showed that 17 of the 21 Pseudomonas strains isolated from the rhizosphere or endosphere of Populus deltoides increased radial growth of Laccaria bicolor in fungal-bacterial cocultures. Some potential mechanisms through which MHB can improve fungal growth include production of compounds such as branching factors that increase hyphal extension by changing the actin cytoskeleton of fungal hyphae (Frey-Klett et al., 2007; Schrey et al., 2007) or through nutritional complementation with vitamins or compounds that are not synthesized by mycorrhizal fungi (Hildebrandt et al., 2006; Deveau et al., 2010). In the study by Labbé et al. (2014), dual inoculation of rooted cuttings of three Populus species with L. bicolor and Pseudomonas strains increased the number of secondary roots and consequently mycorrhizal colonization. Nevertheless, the effects of MHB on root proliferation and morphology are not yet clear but could possibly be modulated through auxin homeostasis and ethylene production by MHB (Deveau and Labbé, 2017).

Other mechanisms by which $\mathrm{MHB}$ are known to promote mycorrhization include amelioration of stresses for better growth of fungi (Frey-Klett et al., 2007). To this effect, Hashem et al. (2016) showed that inoculation of Acacia gerardii with Bacillus subtilis enhanced AMF colonization by alleviating salt stress. As a consequence, plant biomass, nodulation, and crude protein content of $A$. gerardii increased when plants were co-inoculated with AMF and B. subtilis as opposed to independent inoculations with either symbiont. In this study, inoculations of B. subtilis alone or in combination with arbuscular mycorrhizal fungus resulted in higher uptake of $\mathrm{N}, \mathrm{P}, \mathrm{K}, \mathrm{Mg}, \mathrm{Ca}$, enhanced activity of phosphatases and decrease in concentrations of $\mathrm{Na}$ and $\mathrm{Cl}$ in plant tissues that consequently resulted in improved mycorrhizal colonization and plant growth under salinity stress. While there are additional studies showing a positive effect of dual inoculations with bacteria and mycorrhizal fungi on plant growth and stress tolerance (Neeraj and Singh, 2011; Almethyeb et al., 2013; Vafadar et al., 2014), they all represent agricultural or forestry systems. Unfortunately, no literature is available to date that determines if and how MHB functioning shapes plant ecology and evolution in natural systems. It is especially likely that the ecology of partially- or fully mycoheterotrophic plants is more closely tied to MHB functions considering their nearcomplete dependence on mycorrhizal fungi.

\section{Orchid RAB as MHB}

Considering that the life histories of orchids are intimately tied to their mycorrhizal fungal partners whereby OMF may regulate the fundamental niches of orchids by limiting germination, recruitment, and plant fitness (Swarts et al., 2010; Kaur et al., 2019), the potential contributions of MHB in orchid ecology are expected to be appreciable. Yet, to our knowledge, nothing is known of the identity, functions, and interactions of $\mathrm{MHB}$ associated with orchids and their OMF. Given the complete absence of studies on MHB-OMF interactions, some basic queries are warranted as a starting point. These might include an investigation of whether $\mathrm{MHB}$ associated with OMF, orchid 
tissues or orchid rhizosphere improve mycorrhizal colonization either during germination or otherwise. Investigations must also address whether MHB-OMF associations exhibit specificity toward each other and toward their orchid hosts. If such extreme specializations exist in the MHB-OMF-host interactions, their collective potential for explaining plant distributions could be remarkable, and could eventually explain species distributions and community compositions in the context of microbial niche partitioning. For instance, a community of four orchid taxa that utilize a same orchid mycorrhizal fungus might otherwise compete for soil nutrients or soil moisture, whereas their unique specificities toward MHB strains could facilitate access to nonoverlapping nutrient pools such as different chemical forms of nitrogen (ammonium, nitrate, etc.), thereby promoting coexistence through niche differentiation and resource partitioning.

\section{RAB as Constituents of Holobionts and Hologenomes}

Despite the relative infancy of plant-microbial frameworks in explaining functions, distributions, and evolution of plants, plants are no longer viewed as autonomous units (Vandenkoornhuyse et al., 2015). Microbes are implicated in ontogenic, physiological and evolutionarily development of plants (Wagner et al., 2014; Yang et al., 2014; Rosenberg and Zilber-Rosenberg, 2016). Yet, we are far from understanding the coupled effects of the various microbes, their interactions with environment, and even farther from considering holobionts and their hologenomes within these contexts (Vandenkoornhuyse et al., 2015). While the role of microbiota in host plant fitness is somewhat understood (Hassani et al., 2018), the mechanistic underpinnings of hologenomes in shaping plant ecology and evolution remain elusive. The limited empirical evidence of the contribution of hologenomes in evolution and speciation comes mostly from the animal kingdom. Accordingly, the hologenome acted as a reproductive barrier in the parasitoid wasp genus Nasonia (Brucker and Bordenstein, 2013) when hybrids generated by cross-breeding closely related lineages of Nasonia were inviable. In contrast, an antibiotic treatment rescued this hybrid lethality, suggesting that the gut microbiome of the Nasonia species prevented interspecific breeding. Similarly, Sharon et al. (2010) showed that a tetracycline treatment terminated the diet-induced mating preferences in Drosophila melanogaster and that these preferences were reinstated when flies were infected with microbes isolated from their guts. Hence, it is not only conceivable but very likely that similar mechanisms operate in the plant kingdom where microbiota alters reproductive or other biological processes that directly impact ecology and evolution of organisms.

\section{Orchid RAB as Constituents of Holobionts and Hologenomes}

The hologenome concept has a particular relevance for orchids because of their obligate mycoheterotrophic habit during seed germination and the continued dependency on microbes throughout their life cycle depending on their trophic mode. Simultaneously, questions related to the often puzzling distribution of orchids and their rapid diversification into 25,00030,000 species should also perhaps be framed within the context of hologenomes. As such, Givnish et al. (2015) ascribed the radiation in orchids to the evolution of pollinia, epiphytism, crassulacean acid metabolism photosynthesis, deceit pollination and tropical distributions, while leaving out OMF by citing a lack of relevant information. Not surprisingly, bacterial preferences, microbiomes, or hologenomes were not even mentioned as potential predictors in their study. Nevertheless, a few researchers have attempted to link OMF to diversification in photosynthetic orchids (Roche et al., 2010; Waterman et al., 2011; Suárez et al., 2016), suggesting that OMF do not, as yet, explain speciation within orchid lineages. Notably, with the exception of Waterman et al. (2011), each of the other two studies was focused only on a single genus of orchids, limiting the interpretation of these results and leaving much room for continued investigations. In contrast to photosynthetic orchids, the evolution of achlorophyllous, fully mycoheterotrophic orchids and mixotrophic taxa is linked to a shift in their OMF partners (Ogura-Tsujita et al., 2012; Těšitelová et al., 2015). The establishment of new and stable symbioses with microbes requires major physiological adjustments for the host as well as their microbial symbionts, and can lead to coevolution of both partners. For this reason, the switch from mixotrophy to complete mycoheterotrophy is often accompanied by a loss of genes related to photosynthesis and an expansion of the genes involved in digestion of fungal hyphae (Yuan et al., 2018). Although not investigated, similar genomic adaptations could be expected in the mycorrhizal fungal genomes to adapt to the endophytic lifestyle in achlorophyllous orchids. Another classic case of co-evolution is evident in the evolution of endofungal bacteria that persist within AMF and have lost the ability to live independently after undergoing genome reductions (Bonfante et al., 2019). Altogether, the current state of knowledge suggests that genome rearrangements are inevitable in the establishment of highly specialized symbioses, suggesting that a consideration of hologenomes may help explain diversification in orchids.

Besides the evolutionary implications of hologenomes, both spatial and temporal changes in the hologenomic components could help optimize the functioning of holobionts and eventually predict the distribution patterns of orchids. Orchids are represented pan-globally even though the distribution ranges of individual species range from highly endemic (Swarts et al., 2010; Pandey et al., 2013; Kaur et al., 2021) to wide ranging (Hutchings, 2010; Davis et al., 2015; Kaur et al., 2019). Regardless of their distributions, however, a large majority of orchid taxa are faced with declining trends as their local populations, which are often small, are exposed to anthropogenic or environmental threats (Swarts and Dixon, 2009; Fay, 2018). Under such increasingly stressed conditions, genetic variability in hologenomes through differential recruitment of OMF and / or orchid RAB might underpin local adaptations of the orchid holobionts. In particular, association with distinct orchid RAB might be especially beneficial in conferring hologenomic variability when host orchids exhibit extreme specificity (Swarts et al., 2010; Kaur et al., 2018, 2019; Calevo et al., 2020) in their OMF preference. Altogether, we posit that combined considerations of 
OMF, orchid RAB and the host orchid as holobionts and hologenomes, along with their interactions with the environment, thus, merit increasing attention in our efforts to explain the distributions, adaptations, and evolution of orchids.

\section{IMPLICATIONS OF ORCHID RAB FOR ORCHID CONSERVATION}

Acknowledging the pivotal role(s) of bacteria and other microorganisms in the origin and maintenance of plants and biodiversity on the planet, we specifically propose that conservation programs employ a holistic approach that emphasizes conservation of symbiotic microbes along with their hosts and their collective habitats. In fact, we suggest that conservation programs should also adopt a holobiont perspective when designing tools and strategies to preserve and protect ecosystems and their biotic components. This approach is especially suited and necessary for the Orchidaceae that are all considered 'rare' in nature, represent approximately $10 \%$ of all angiosperm flora on earth (and $80 \%$ of the protected species on the Convention on International Trade in Endangered Species of Wild Fauna and Flora appendices; Fay, 2018), are obligate mycoheterotrophic during germination, and represent some of the most unique evolutionary strategies among higher plants. Yet, their bilateral or multilateral interactions with bacteria remain sorely neglected. We posit that while a deeper understanding of the role of MHB may seem more urgent with respect to orchid conservation, all endophytic and epiphytic microbes deserve consideration to inform holistic conservation that embraces the functional roles of microbes in individual plants, and their capacity to regulate plant growth, species distributions, species interactions, evolution, and ecosystem functions. While such efforts are warranted, they also require a clear understanding of the contributions of distinct organisms individually and altogether. For instance, the knowledge of the structure and function of bacterial guilds associated with orchid roots is extremely limited at present though some distinct trends are noticeable and informative. As such, mirroring the patterns of OMF availability in soil, orchid RAB also tend to have lower abundances in rhizosphere soil (Kaur et al., 2020). This

\section{REFERENCES}

Afzal, I., Shinwari, Z. K., Sikandar, S., and Shahzad, S. (2019). Plant beneficial endophytic bacteria: mechanisms, diversity, host range and genetic determinants. Microbiol. Res. 221, 36-49. doi: 10.1016/j.micres.2019.02.001

Alibrandi, P., Schnell, S., Perotto, S., and Cardinale, M. (2020). Diversity and structure of the endophytic bacterial communities associated with three terrestrial orchid species as revealed by 16S rRNA gene metabarcoding. Front. Microbiol. 11:3207. doi: 10.3389/fmicb.2020.604964

Almethyeb, M., Ruppel, S., Paulsen, H. M., Vassilev, N., and Eichler-Löbermann, B. (2013). Single and combined applications of arbuscular mycorrhizal fungi and Enterobacter radicincitans affect nutrient uptake of faba bean and soil biological characteristics. Appl. Agric. Forestry Res. 3, 229-234. doi: 10.3220/LBF-2013229-234

Arkhipova, T. N., Veselov, S. U., Melentiev, A. I., Martynenko, E. V., and Kudoyarova, G. R. (2005). Ability of bacterium Bacillus subtilis to produce observation suggests that orchid $\mathrm{RAB}$ likely remain restricted primarily to the perennating tubers without maintaining a significant presence outside the orchid tissues. Simultaneously, if orchid RAB primarily represent $\mathrm{MHB}$, then the current OMF paradigm may need to be reconsidered entirely. In essence, it may not just be the OMF but the coupling of OMF along with their $\mathrm{MHB}$ that regulate orchid germination and growth.

\section{CONCLUSION}

Microbes are increasingly being understood to modulate plant distributions and productivity (Van Der Heijden et al., 2008). After plants, bacteria form the largest proportion of the global biomass (Bar-On et al., 2018). Combined with their current dominance, the relatively recent understanding of their evolutionary role in respiration, photosynthesis, and terrestrialization of plants (Cheng et al., 2019) points to the fact that scientists are only beginning to understand the role of bacteria in plant biology and ecology. While the symbiosis between eukaryotes and plastids has existed for $1.5 \mathrm{Ga}$, nitrogenfixation in symbiosis with legumes is estimated to have originated about 66 mya (Doyle, 2011; Shih and Matzke, 2013). With long evolutionary histories of intimate partnerships that have driven plant evolution, it would hardly be surprising to discover additional plant functions that are underpinned by root associated bacteria.

Altogether, the largely neglected roles of microbes, including bacteria, in modulating plant and ecosystem functions deserve a deeper understanding and consideration in conservation programs. Fortunately, technological advances are assisting such efforts by allowing scientists to profile microbial communities and functions at a more accelerated pace. We suggest that the time is upon us to holistically examine, understand, and incorporate bacteria and their communities in the science and practice of orchid ecology and conservation.

\section{AUTHOR CONTRIBUTIONS}

Both authors conceived the idea and wrote and reviewed the manuscript.

cytokinins and to influence the growth and endogenous hormone content of lettuce plants. Plant Soil 272, 201-209. doi: 10.1007/s11104-004-5047-x

Baack, E., Melo, M. C., Rieseberg, L. H., and Ortiz-Barrientos, D. (2015). The origins of reproductive isolation in plants. New Phytol. 207, 968-984. doi: 10.1111/nph.13424

Bar-On, Y. M., Phillips, R., and Milo, R. (2018). The biomass distribution on Earth. Proc. Natl. Acad. Sci. U.S.A. 115, 6506-6511. doi: 10.1073/pnas.1711842115

Bonfante, P., and Anca, I. (2009). Plants, mycorrhizal fungi, and bacteria: a network of interactions. Annu. Rev. Microbiol. 63, 363-383. doi: 10.1146/annurev.micro. 091208.073504

Bonfante, P., Venice, F., and Lanfranco, L. (2019). The mycobiota: fungi take their place between plants and bacteria. Curr. Opin. Microbiol. 49, 18-25. doi: 10.1016/j.mib.2019.08.004

Bouffaud, M. L., Poirier, M. A., Muller, D., and Moënne-Loccoz, Y. (2014). Root microbiome relates to plant host evolution in maize and other Poaceae. Environ. Microbiol. 16, 2804-2814. doi: 10.1111/1462-2920.12442 
Brock, A. K., Berger, B., Mewis, I., and Ruppel, S. (2013). Impact of the PGPB Enterobacter radicincitans DSM 16656 on growth, glucosinolate profile, and immune responses of Arabidopsis thaliana. Microb. Ecol. 65, 661-670. doi: 10.1007/s00248-012-0146-3

Brucker, R. M., and Bordenstein, S. R. (2013). The hologenomic basis of speciation: gut bacteria cause hybrid lethality in the genus Nasonia. Science 341, 667-669. doi: 10.1126/science.1240659

Bulgarelli, D., Schlaeppi, K., Spaepen, S., van Themaat, E. V. L., and SchulzeLefert, P. (2013). Structure and functions of the bacterial microbiota of plants. Annu. Rev. Plant Biol. 64, 807-838. doi: 10.1146/annurev-arplant-050312120106

Calevo, J., Voyron, S., Ercole, E., and Girlanda, M. (2020). Is the distribution of two rare Orchis sister species limited by their main mycobiont? Diversity 12:262. doi: 10.3390/D12070262

Chen, L., Swenson, N. G., Ji, N., Mi, X., Ren, H., Guo, L., et al. (2019). Differential soil fungus accumulation and density dependence of trees in a subtropical forest. Science 366, 124-128. doi: 10.1126/science.aau1361

Cheng, S., Xian, W., Fu, Y., Marin, B., Keller, J., Wu, T., et al. (2019). Genomes of subaerial Zygnematophyceae provide insights into land plant evolution. Cell 179, 1057-1067. doi: 10.1016/j.cell.2019.10.019

Chung, Y. A., and Rudgers, J. A. (2016). Plant-soil feedbacks promote negative frequency dependence in the coexistence of two aridland grasses. Proc. R. Soc. B Biol. Sci. 283:20160608. doi: 10.1098/rspb.2016.0608

Davis, B. J., Phillips, R. D., Wright, M., Linde, C. C., and Dixon, K. W. (2015). Continent-wide distribution in mycorrhizal fungi: implications for the biogeography of specialized orchids. Ann. Bot. 116, 413-421. doi: 10.1093/aob/ mcv084

Deveau, A., Brulé, C., Palin, B., Champmartin, D., Rubini, P., Garbaye, J., et al. (2010). Role of fungal trehalose and bacterial thiamine in the improved survival and growth of the ectomycorrhizal fungus Laccaria bicolor $5238 \mathrm{~N}$ and the helper bacterium Pseudomonas fluorescens BBc6R8. Environ. Microbiol. Rep. 2, 560-568. doi: 10.1111/j.1758-2229.2010.00145.x

Deveau, A., and Labbé, J. (2017). "Mycorrhiza helper bacteria," in Molecular Mycorrhizal Symbiosis, ed. F. Martin (Hoboken, NJ: Wiley Blackwell), 437-440.

Ding, S., Huang, C. L., Sheng, H. M., Song, C. L., Li, Y. B., and An, L. Z. (2011). Effect of inoculation with the endophyte Clavibacter sp. strain Enf12 on chilling tolerance in Chorispora bungeana. Physiol. Plant. 141, 141-151. doi: 10.1111/j. 1399-3054.2010.01428.x

Doyle, J. J. (2011). Phylogenetic perspectives on the origins of nodulation. Mol. Plant Microbe Interact. 24, 1289-1295. doi: 10.1094/MPMI-05-11-0114

Fay, M. F. (2018). Orchid conservation: how can we meet the challenges in the twenty-first century? Bot. Stud. 59:16. doi: 10.1186/s40529-018-0 $232-\mathrm{z}$

Frey-Klett, P., Garbaye, J., and Tarkka, M. (2007). The mycorrhiza helper bacteria revisited. New Phytol. 176, 22-36. doi: 10.1111/j.1469-8137.2007.02191.x

Garbaye, J. (1994). Helper bacteria: a new dimension to the mycorrhizal symbiosis. New Phytol. 128, 197-210. doi: 10.1111/j.1469-8137.1994.tb04003.x

García Parisi, P. A., Lattanzi, F. A., Grimoldi, A. A., and Omacini, M. (2015). Multi-symbiotic systems: functional implications of the coexistence of grassendophyte and legume-rhizobia symbioses. Oikos 124, 553-560. doi: 10.1111/ oik.01540

Givnish, T. J., Spalink, D., Ames, M., Lyon, S. P., Hunter, S. J., Zuluaga, A., et al. (2015). Orchid phylogenomics and multiple drivers of their extraordinary diversification. Proc. R. Soc. B Biol. Sci. 282:20151553. doi: 10.1098/rspb.2015. 1553

Glaeser, S. P., Imani, J., Alabid, I., Guo, H., Kumar, N., Kampfer, P., et al. (2016). Non-pathogenic Rhizobium radiobacter F4 deploys plant beneficial activity independent of its host Piriformospora indica. ISME J. 10, 871-884. doi: 10. 1038/ismej.2015.163

Glick, B. R. (2012). Plant growth-promoting bacteria: mechanisms and applications. Scientifica 2012, 1-15. doi: 10.6064/2012/963401

Glick, B. R. (2014). Bacteria with ACC deaminase can promote plant growth and help to feed the world. Microbiol. Res. 169, 30-39. doi: 10.1016/j.micres.2013. 09.009

Gontijo, J. B., Andrade, G. V. S., Baldotto, M. A., and Baldotto, L. E. B. (2018). Bioprospecting and selection of growth-promoting bacteria for Cymbidium sp. orchids. Sci. Agric. 75, 368-374. doi: 10.1590/1678-992x-2017-0117
Gupta, G., Panwar, J., and Jha, P. N. (2013). Natural occurrence of Pseudomonas aeruginosa, a dominant cultivable diazotrophic endophytic bacterium colonizing Pennisetum glaucum (L.) R. Br. Appl. Soil Ecol. 64, 252-261. doi: 10.1016/j.apsoil.2012.12.016

Hannula, S. E., Ma, H. K., Pérez-Jaramillo, J. E., Pineda, A., and Bezemer, T. M. (2020). Structure and ecological function of the soil microbiome affecting plant-soil feedbacks in the presence of a soil-borne pathogen. Environ. Microbiol. 22, 660-676. doi: 10.1111/1462-2920.14882

Hashem, A., Abd-Allah, E. F., Alqarawi, A. A., Al-Huqail, A. A., Wirth, S., and Egamberdieva, D. (2016). The interaction between arbuscular mycorrhizal fungi and endophytic bacteria enhances plant growth of Acacia gerrardii under salt stress. Front. Microbiol. 7:1089. doi: 10.3389/fmicb.2016.01089

Hassani, M. A., Durán, P., and Hacquard, S. (2018). Microbial interactions within the plant holobiont. Microbiome 6:58. doi: 10.1186/s40168-018-0445-0

He, R., Zeng, J., Zhao, D., Huang, R., Yu, Z., and Wu, L. (2020). Contrasting patterns in diversity and community assembly of Phragmites australis rootassociated bacterial communities from different seasons. Appl. Environ. Microbiol. 86:e00379-20. doi: 10.1128/AEM.00379-20

Herrera, H., Sanhueza, T., Novotná, A., Charles, T. C., and Arriagada, C. (2020). Isolation and identification of endophytic bacteria from mycorrhizal tissues of terrestrial orchids from Southern Chile. Diversity 12:55. doi: 10.3390/ d12020055

Hildebrandt, U., Ouziad, F., Marner, F. J., and Bothe, H. (2006). The bacterium Paenibacillus validus stimulates growth of the arbuscular mycorrhizal fungus Glomus intraradices up to the formation of fertile spores. FEMS Microbiol. Lett. 254, 258-267. doi: 10.1111/j.1574-6968.2005.0 0027.x

Hoffman, M. T., Gunatilaka, M. K., Wijeratne, K., Gunatilaka, L., and Arnold, A. E. (2013). Endohyphal bacterium enhances production of Indole-3-Acetic Acid by a foliar fungal endophyte. PLoS One 8:e73132. doi: 10.1371/journal.pone. 0073132

Hutchings, M. J. (2010). The population biology of the early spider orchid Ophrys sphegodes Mill. III. demography over three decades. J. Ecol. 98, 867-878. doi: 10.1111/j.1365-2745.2010.01661.x

Júnior, R. F. G., Pedrinho, E. A. N., Castellane, T. C. L., and Lemos, E. G. D. M. (2011). Auxin-producing bacteria isolated from the roots of Cattleya walkeriana, an endangered Brazilian orchid, and their role in acclimatization. Rev. Bras. Ciência Do Solo 35, 729-737. doi: 10.1590/S010006832011000300008

Kang, S. M., Khan, A. L., Hussain, J., Ali, L., Kamran, M., Waqas, M., et al. (2012). Rhizonin A from Burkholderia sp. KCTC11096 and its growth promoting role in lettuce seed germination. Molecules 17, 7980-7988. doi: 10.3390/ molecules 17077980

Kang, S. M., Radhakrishnan, R., Khan, A. L., Kim, M. J., Park, J. M., Kim, B. R., et al. (2014). Gibberellin secreting rhizobacterium, Pseudomonas putida H-23 modulates the hormonal and stress physiology of soybean to improve the plant growth under saline and drought conditions. Plant Physiol. Biochem. 84, 115-124. doi: 10.1016/j.plaphy.2014.09.001

Kaur, J., Andrews, L., and Sharma, J. (2019). High specificity of a rare terrestrial orchid toward a rare fungus within the North American Tallgrass Prairie. Fungal Biol. 123, 895-904. doi: 10.1016/j.funbio.2019.09.010

Kaur, J., Harder, C. B., and Sharma, J. (2020). Characterization of Endophytic Bacterial Communities in Congeneric Temperate Orchids with Soil, Host Phenology and Population Size as the Predictors. Washington, DC: Ecological Society of America.

Kaur, J., Phillips, C., and Sharma, J. (2021). Host population size is linked to orchid mycorrhizal fungal communities in roots and soil, which are shaped by microenvironment. Mycorrhiza 31, 17-30. doi: 10.1007/s00572-020-00 993-5

Kaur, J., Poff, K., and Sharma, J. (2018). A rare temperate terrestrial orchid selects similar Tulasnella taxa in ex situ and in situ environments. Plant Ecol. 219, 45-55. doi: 10.1007/s11258-017-0776-0

Khan, A. L., Waqas, M., Kang, S. M., Al-Harrasi, A., Hussain, J., Al-Rawahi, A., et al. (2014). Bacterial endophyte Sphingomonas sp. LK11 produces gibberellins and IAA and promotes tomato plant growth. J. Microbiol. 52, 689-695. doi: 10.1007/s12275-014-4002-7

Koziol, L., and Bever, J. D. (2017). The missing link in grassland restoration: arbuscular mycorrhizal fungi inoculation increases plant diversity and 
accelerates succession. J. Appl. Ecol. 54, 1301-1309. doi: 10.1111/1365-2664. 12843

Krishna, M., Gupta, S., Delgado-Baquerizo, M., Morriën, E., Garkoti, S. C., Chaturvedi, R., et al. (2020). Successional trajectory of bacterial communities in soil are shaped by plant-driven changes during secondary succession. Sci. Rep. 10:9864. doi: 10.1038/s41598-020-66638-x

Kurth, F., Zeitler, K., Feldhahn, L., Neu, T. R., Weber, T., Kristufek, V., et al. (2013). Detection and quantification of a mycorrhization helper bacterium and a mycorrhizal fungus in plant-soil microcosms at different levels of complexity. BMC Microbiol. 13:205. doi: 10.1186/1471-2180-13-205

Kusari, P., Kusari, S., Lamshöft, M., Sezgin, S., Spiteller, M., and Kayser, O. (2014). Quorum quenching is an antivirulence strategy employed by endophytic bacteria. Appl. Microbiol. Biotechnol. 98, 7173-7183. doi: 10.1007/s00253-0145807-3

Labbé, J. L., Weston, D. J., Dunkirk, N., Pelletier, D. A., and Tuskan, G. A. (2014). Newly identified helper bacteria stimulate ectomycorrhizal formation in Populus. Front. Plant Sci. 5:579. doi: 10.3389/fpls.2014.00579

Li, O., Xiao, R., Sun, L., Guan, C., Kong, D., and Hu, X. (2017). Bacterial and diazotrophic diversities of endophytes in Dendrobium catenatum determined through barcoded pyrosequencing. PLoS One 12:e0184717. doi: 10.1371/ journal.pone.0184717

Lin, M., Xiong, H., Xiang, X., Zhou, Z., Liang, L., and Mei, Z. (2020). The effect of plant geographical location and developmental stage on root-associated microbiomes of Gymnadenia conopsea. Front. Microbiol. 11:1257. doi: 10.3389/ fmicb.2020.01257

Liu, F., Xing, S., Ma, H., Du, Z., and Ma, B. (2013). Cytokinin-producing, plant growth-promoting rhizobacteria that confer resistance to drought stress in Platycladus orientalis container seedlings. Appl. Microbiol. Biotechnol. 97, 91559164. doi: 10.1007/s00253-013-5193-2

Liu, H., Carvalhais, L. C., Crawford, M., Singh, E., Dennis, P. G., Pieterse, C. M., et al. (2017). Inner plant values: diversity, colonization and benefits from endophytic bacteria. Front. Microbiol. 8:2552. doi: 10.3389/fmicb.2017.02552

Lu, T., Ke, M., Lavoie, M., Jin, Y., Fan, X., Zhang, Z., et al. (2018). Rhizosphere microorganisms can influence the timing of plant flowering. Microbiome 6:231. doi: 10.1186/s40168-018-0615-0

Margulis, L. (1991). “Symbiogenesis and symbionticism," in Symbiosis as a Source of Evolutionary Innovation: Speciation and Morphogenesis, eds L. Margulis and R. Fester (Cambridge, MA: MIT Press), 1-14.

Martin, F. M., Uroz, S., and Barker, D. G. (2017). Ancestral alliances: plant mutualistic symbioses with fungi and bacteria. Science 356:eaad4501. doi: 10 . 1126/science.aad4501

Marupakula, S., Mahmood, S., and Finlay, R. D. (2016). Analysis of single root tip microbiomes suggests that distinctive bacterial communities are selected by Pinus sylvestris roots colonized by different ectomycorrhizal fungi. Environ. Microbiol. 18, 1470-1483. doi: 10.1111/1462-2920.13102

McCormick, M. K., Taylor, D. L., Whigham, D. F., and Burnett, R. K. (2016). Germination patterns in three terrestrial orchids relate to abundance of mycorrhizal fungi. J. Ecol. 104, 744-754. doi: 10.1111/1365-2745.12556

Miki, T. (2012). Microbe-mediated plant-soil feedback and its roles in a chnaging world. Ecol. Res. 27, 509-520. doi: 10.1007/s11284-012-0937-5

Mukhtar, S., Mirza, B. S., Mehnaz, S., Mirza, M. S., Mclean, J., and Malik, K. A. (2018). Impact of soil salinity on the microbial structure of halophyte rhizosphere microbiome. World J. Microbiol. Biotechnol. 34, 1-17. doi: 10.1007/ s11274-018-2509-5

Neeraj, and Singh, K. (2011). Organic amendments to soil inoculated arbuscular mycorrhizal fungi and Pseudomonas fluorescens treatments reduce the development of root-rot disease and enhance the yield of Phaseolus vulgaris L. Eur. J. Soil Biol. 47, 288-295. doi: 10.1016/j.ejsobi.2011.07.002

Nett, R. S., Nguyen, H., Nagel, R., Marcassa, A., Charles, T. C., Friedberg, I., et al. (2020). Unraveling a tangled skein: evolutionary analysis of the bacterial gibberellin biosynthetic operon. mSphere 5:e00292-20. doi: 10.1128/msphere. 00292-20

Nguyen, N. H., and Bruns, T. D. (2015). The microbiome of Pinus muricata ectomycorrhizae: community assemblages, fungal species effects, and Burkholderia as important bacteria in multipartnered symbioses. Microb. Ecol. 69, 914-921. doi: 10.1007/s00248-015-0574-y

Novotná, A., and Suárez, J. P. (2018). Molecular detection of bacteria associated with Serendipita sp., a mycorrhizal fungus from the orchid Stanhopea connata
Klotzsch in southern Ecuador. Bot. Lett. 165, 307-313. doi: 10.1080/23818107. 2018.1436087

Ogura-Tsujita, Y., Yokoyama, J., Miyoshi, K., and Yukawa, T. (2012). Shifts in mycorrhizal fungi during the evolution of autotrophy to mycoheterotrophy in Cymbidium (Orchidaceae). Am. J. Bot. 99, 1158-1176. doi: 10.3732/ajb. 1100464

Pandey, M., Sharma, J., Taylor, D. L., and Yadon, V. L. (2013). A narrowly endemic photosynthetic orchid is non-specific in its mycorrhizal associations. Mol. Ecol. 22, 2341-2354. doi: 10.1111/mec.12249

Panke-Buisse, K., Poole, A. C., Goodrich, J. K., Ley, R. E., and Kao-Kniffin, J. (2015). Selection on soil microbiomes reveals reproducible impacts on plant function. ISME J. 9, 980-989. doi: 10.1038/ismej.2014.196

Patten, C. L., and Glick, B. R. (2002). Role of Pseudomonas putida indoleacetic acid in development of the host plant root system. Appl. Environ. Microbiol. 68, 3795-3801. doi: 10.1128/AEM.68.8.3795-3801.2002

Peiffer, J. A., Spor, A., Koren, O., Jin, Z., Tringe, S. G., Dangl, J. L., et al. (2013). Diversity and heritability of the maize rhizosphere microbiome under field conditions. Proc. Natl. Acad. Sci. U.S.A. 110, 6548-6553. doi: 10.1073/pnas. 1302837110

Pii, Y., Mimmo, T., Tomasi, N., Terzano, R., Cesco, S., and Crecchio, C. (2015). Microbial interactions in the rhizosphere: beneficial influences of plant growthpromoting rhizobacteria on nutrient acquisition process. A review. Biol. Fertil. Soils 51, 403-415. doi: 10.1007/s00374-015-0996-1

Qin, S., Zhang, Y. J., Yuan, B., Xu, P. Y., Xing, K., Wang, J., et al. (2014). Isolation of ACC deaminase-producing habitat-adapted symbiotic bacteria associated with halophyte Limonium sinense (Girard) Kuntze and evaluating their plant growth-promoting activity under salt stress. Plant Soil 374, 753-766. doi: 10. 1007/s11104-013-1918-3

Rajkumar, M., Ae, N., and Freitas, H. (2009). Endophytic bacteria and their potential to enhance heavy metal phytoextraction. Chemosphere 77, 153-160. doi: 10.1016/j.chemosphere.2009.06.047

Roche, S. A., Carter, R. J., Peakall, R., Smith, L. M., Whitehead, M. R., and Linde, C. C. (2010). A narrow group of monophyletic Tulasnella (Tulasnellaceae) symbiont lineages are associated with multiple species of Chiloglottis (Orchidaceae): implications for orchid diversity. Am. J. Bot. 97, 1313-1327. doi: 10.3732/ajb.1000049

Rosenberg, E., and Zilber-Rosenberg, I. (2016). Microbes drive evolution of animals and plants: the hologenome concept. mBio 7:e01395-15. doi: 10.1128/ mBio.01395-15

Rosenberg, E., and Zilber-Rosenberg, I. (2018). The hologenome concept of evolution after 10 years. Microbiome 6:78. doi: 10.1186/s40168-018-0457-9

Santoyo, G., Moreno-Hagelsieb, G., del Carmen Orozco-Mosqueda, M., and Glick, B. R. (2016). Plant growth-promoting bacterial endophytes. Microbiol. Res. 183, 92-99. doi: 10.1016/j.micres.2015.11.008

Scherling, C., Ulrich, K., Ewald, D., and Weckwerth, W. (2009). A metabolic signature of the beneficial interaction of the endophyte Paenibacillus sp. isolate and in vitro-grown poplar plants revealed by metabolomics. Mol. Plant Microbe Interact. 22, 1032-1037. doi: 10.1094/MPMI-22-8-1032

Schrey, S. D., Salo, V., Raudaskoski, M., Hampp, R., Nehls, U., and Tarkka, M. T. (2007). Interaction with mycorrhiza helper bacterium Streptomyces sp. AcH 505 modifies organisation of actin cytoskeleton in the ectomycorrhizal fungus Amanita muscaria (fly agaric). Curr. Genet. 52, 77-85. doi: 10.1007/s00294007-0138-x

Semchenko, M., Leff, J. W., Lozano, Y. M., Saar, S., Davison, J., Wilkinson, A., et al. (2018). Fungal diversity regulates plant-soil feedbacks in temperate grassland. Sci. Adv. 4:eaau4578. doi: 10.1126/sciadv.aau4578

Sharon, G., Segal, D., Ringo, J. M., Hefetz, A., Rosenberg, I., and Rosenberg, E. (2010). Commensal bacteria play a role in mating preference of Drosophila melanogaster. Proc. Natl. Acad. Sci. U.S.A. 107, 20051-20056. doi: 10.1073/pnas. 1009906107

Shefferson, R. P., Jacquemyn, H., Kull, T., and Hutchings, M. J. (2020). The demography of terrestrial orchids: life history, population dynamics and conservation. Bot. J. Linn. Soc. 192, 315-332. doi: 10.1093/botlinnean/boz084

Shefferson, R. P., Kull, T., Hutchings, M. J., Selosse, M. A., Jacquemyn, H., Kellett, K. M., et al. (2018). Drivers of vegetative dormancy across herbaceous perennial plant species. Ecol. Lett. 21, 724-733. doi: 10.1111/ele.12940

Sheibani-Tezerji, R., Rattei, T., Sessitsch, A., Trognitz, F., and Mitter, B. (2015). Transcriptome profiling of the endophyte Burkholderia phytofirmans psin 
indicates sensing of the plant environment and drought stress. mBio 6:e0062115. doi: 10.1128/mBio.00621-15

Shih, P. M., and Matzke, N. J. (2013). Primary endosymbiosis events date to the later Proterozoic with cross-calibrated phylogenetic dating of duplicated ATPase proteins. Proc. Natl. Acad. Sci. U.S.A. 110, 12355-12360. doi: 10.1073/ pnas. 1305813110

Siefert, A., Zillig, K. W., Friesen, M. L., and Strauss, S. Y. (2019). Mutualists stabilize the coexistence of congeneric legumes. Am. Nat. 193, 200-212. doi: $10.1086 / 701056$

Singh, B. K., Nunan, N., Ridgway, K. P., McNicol, J., Young, J. P. W., Daniell, T. J., et al. (2008). Relationship between assemblages of mycorrhizal fungi and bacteria on grass roots. Environ. Microbiol. 10, 534-541. doi: 10.1111/j.14622920.2007.01474.x

Srivastava, S., Bist, V., Srivastava, S., Singh, P. C., Trivedi, P. K., Asif, M. H., et al. (2016). Unraveling aspects of Bacillus amyloliquefaciens mediated enhanced production of rice under biotic stress of Rhizoctonia solani. Front. Plant Sci. 7:587. doi: 10.3389/fpls.2016.00587

Suárez, J. P., Eguiguren, J. S., Herrera, P., and Jost, L. (2016). Do mycorrhizal fungi drive speciation in Teagueia (Orchidaceae) in the upper Pastaza watershed of Ecuador? Symbiosis 69, 161-168. doi: 10.1007/s13199-016-0 399-6

Subramanian, P., Mageswari, A., Kim, K., Lee, Y., and Sa, T. (2015). Psychrotolerant endophytic Pseudomonas sp. strains OB155 and OS261 induced chilling resistance in tomato plants (Solanum lycopersicum Mill.) by activation of their antioxidant capacity. Mol. Plant Microbe Interact. 28, 1073-1081. doi: 10.1094/ MPMI-01-15-0021-R

Sun, Y., Cheng, Z., and Glick, B. R. (2009). The presence of a 1aminocyclopropane-1-carboxylate (ACC) deaminase deletion mutation alters the physiology of the endophytic plant growth-promoting bacterium Burkholderia phytofirmans PsJN. FEMS Microbiol. Lett. 296, 131-136. doi: 10. 1111/j.1574-6968.2009.01625.x

Swarts, N. D., and Dixon, K. W. (2009). Perspectives on orchid conservation in botanic gardens. Trends Plant Sci. 14, 590-598. doi: 10.1016/j.tplants.2009.07. 008

Swarts, N. D., Sinclair, E. A., Francis, A., and Dixon, K. W. (2010). Ecological specialization in mycorrhizal symbiosis leads to rarity in an endangered orchid. Mol. Ecol. 19, 3226-3242. doi: 10.1111/j.1365-294X.2010.04 736.x

Teixeira da Silva, J. A., Tsavkelova, E. A., Zeng, S., Ng, T. B., Parthibhan, S., Dobranszki, J., et al. (2015). Symbiotic in vitro seed propagation of Dendrobium: fungal and bacterial partners and their influence on plant growth and development. Planta 242, 1-22. doi: 10.1007/s00425-0152301-9

Těšitelová, T., Kotilínek, M., Jersáková, J., Joly, F. X., Košnar, J., Tatarenko, I., et al. (2015). Two widespread green Neottia species (Orchidaceae) show mycorrhizal preference for Sebacinales in various habitats and ontogenetic stages. Mol. Ecol. 24, 1122-1134. doi: 10.1111/mec.13088

Tiwari, S., Lata, C., Chauhan, P. S., and Nautiyal, C. S. (2016). Pseudomonas putida attunes morphophysiological, biochemical and molecular responses in Cicer arietinum L. during drought stress and recovery. Plant Physiol. Biochem. 99, 108-117. doi: 10.1016/j.plaphy.2015.11.001

Toumatia, O., Compant, S., Yekkour, A., Goudjal, Y., Sabaou, N., Mathieu, F., et al. (2016). Biocontrol and plant growth promoting properties of Streptomyces mutabilis strain IA1 isolated from a Saharan soil on wheat seedlings and visualization of its niches of colonization. S. Afr. J. Bot. 105, 234-239. doi: 10.1016/j.sajb.2016.03.020

Tsavkelova, E. A., Cherdyntseva, T. A., Botina, S. G., and Netrusov, A. I. (2007a). Bacteria associated with orchid roots and microbial production of auxin. Microbiol. Res. 162, 69-76. doi: 10.1016/j.micres.2006. 07.014

Tsavkelova, E. A., Cherdyntseva, T. A., Klimova, S. Y., Shestakov, A. I., Botina, S. G., and Netrusov, A. I. (2007b). Orchid-associated bacteria produce indole-3-acetic acid, promote seed germination, and increase their microbial yield in response to exogenous auxin. Arch. Microbiol. 188, 655-664. doi: 10.1007/s00203-0070286-x

Tsavkelova, E. A., Cherdyntseva, T. A., Lobakova, E. S., Kolomeitseva, G. L., and Netrusov, A. I. (2001). Microbiota of the orchid rhizoplane. Microbiology 70, 492-497. doi: 10.1023/A:1010402715376
Tsavkelova, E. A., Cherdyntseva, T. A., and Netrusov, A. I. (2004). Bacteria associated with the roots of epiphytic orchids. Microbiology 73, 710-715. doi: 10.1007/s11021-005-0013-Z

Tsavkelova, E. A., Egorova, M. A., Leontieva, M. R., Malakho, S. G., Kolomeitseva, G. L., and Netrusov, A. I. (2016). Dendrobium nobile Lindl. seed germination in co-cultures with diverse associated bacteria. Plant Growth Regul. 80, 79-91. doi: 10.1007/s10725-016-0155-1

Vafadar, F., Amooaghaie, R., and Otroshy, M. (2014). Effects of plant-growthpromoting rhizobacteria and arbuscular mycorrhizal fungus on plant growth, stevioside, NPK, and chlorophyll content of Stevia rebaudiana. J. Plant Interact. 9, 128-136. doi: 10.1080/17429145.2013.779035

Van Der Heijden, M. G. A., Bardgett, R. D., and Van Straalen, N. M. (2008). The unseen majority: soil microbes as drivers of plant diversity and productivity in terrestrial ecosystems. Ecol. Lett. 11, 296-310. doi: 10.1111/j.1461-0248.2007. 01139.x

Van Der Heijden, M. G. A., Bruin, S. D., Luckerhoff, L., Van Logtestijn, R. S. P., and Schlaeppi, K. (2016). A widespread plant-fungal-bacterial symbiosis promotes plant biodiversity, plant nutrition and seedling recruitment. ISME J. 10, 389399. doi: 10.1038/ismej.2015.120

Vandenkoornhuyse, P., Quaiser, A., Duhamel, M., Le Van, A., and Dufresne, A. (2015). The importance of the microbiome of the plant holobiont. New Phytol. 206, 1196-1206. doi: 10.1111/nph.13312

Vestergård, M., Henry, F., Rangel-Castro, J. I., Michelsen, A., Prosser, J. I., and Christensen, S. (2008). Rhizosphere bacterial community composition responds to arbuscular mycorrhiza, but not to reductions in microbial activity induced by foliar cutting. FEMS Microbiol. Ecol. 64, 78-89. doi: 10.1111/j.15746941.2008.00447.x

Wagner, M. R., Lundberg, D. S., Coleman-Derr, D., Tringe, S. G., Dangl, J. L., and Mitchell-Olds, T. (2014). Natural soil microbes alter flowering phenology and the intensity of selection on flowering time in a wild Arabidopsis relative. Ecol. Lett. 17, 717-726. doi: 10.1111/ele.12276

Walia, A., Mehta, P., Chauhan, A., and Shirkot, C. K. (2014). Effect of Bacillus subtilis strain CKT1 as inoculum on growth of tomato seedlings under net house conditions. Proc. Natl. Acad. Sci. India Sect. B Biol. Sci. 84, 145-155. doi: 10.1007/s40011-013-0189-3

Wang, G., Schultz, P., Tipton, A., Zhang, J., Zhang, F., and Bever, J. D. (2019). Soil microbiome mediates positive plant diversity-productivity relationships in late successional grassland species. Ecol. Lett. 22, 1221-1232. doi: 10.1111/ele.1 3273

Wang, X., Yam, T. W., Meng, Q., Zhu, J., Zhang, P., Wu, H., et al. (2016). The dual inoculation of endophytic fungi and bacteria promotes seedlings growth in Dendrobium catenatum (Orchidaceae) under in vitro culture conditions. Plant Cell. 126, 523-531. doi: 10.1007/s11240-016-1021-6

Waterman, R. J., Bidartondo, M. I., Stofberg, J., Combs, J. K., Gebauer, G., Savolainen, V., et al. (2011). The effects of above- and belowground mutualisms on orchid speciation and coexistence. Am. Nat. 177, E54-E68. doi: 10.1086/ 657955

Wilkinson, K. G., Dixon, K. W., and Sivasithamparam, K. (1989). Interaction of soil bacteria, mycorrhizal fungi and orchid seed in relation to germination of Australian orchids. New Phytol. 112, 429-435. doi: 10.1111/j.1469-8137.1989. tb00334.x

Wilkinson, K. G., Dixon, K. W., Sivasithamparam, K., and Ghisalberti, E. L. (1994). Effect of IAA on symbiotic germination of an Australian orchid and its production by orchid-associated bacteria. Plant Soil 159, 291-295. doi: 10. 1007/BF00009292

Yang, S., Zhang, X., Cao, Z., Zhao, K., Wang, S., Chen, M., et al. (2014). Growthpromoting Sphingomonas paucimobilis ZJSH1 associated with Dendrobium officinale through phytohormone production and nitrogen fixation. Microb. Biotechnol. 7, 611-620. doi: 10.1111/1751-7915.12148

Yeoh, Y. K., Dennis, P. G., Paungfoo-Lonhienne, C., Weber, L., Brackin, R., Ragan, M. A., et al. (2017). Evolutionary conservation of a core root microbiome across plant phyla along a tropical soil chronosequence. Nat. Commun. 8:215. doi: 10.1038/s41467-017-00262-8

Yu, J., Zhou, X. F., Yang, S. J., Liu, W. H., and Hu, X. F. (2013). Design and application of specific 16S rDNA-targeted primers for assessing endophytic diversity in Dendrobium officinale using nested PCR-DGGE. Appl. Microbiol. Biotechnol. 97, 9825-9836. doi: 10.1007/s00253-013-5 294-y 
Yuan, Y., Jin, X., Liu, J., Zhao, X., Zhou, J., Wang, X., et al. (2018). The Gastrodia elata genome provides insights into plant adaptation to heterotrophy. Nat. Commun. 9:1615. doi: 10.1038/s41467-018-03423-5

Zhang, J., Ai, Z., Xu, H., Liu, H., Wang, G., Deng, L., et al. (2020). Plant-microbial feedback in secondary succession of semiarid grasslands. Sci. Total Environ. 760:143389. doi: 10.1016/j.scitotenv.2020.143389

Zhang, P., Jin, T., Sahu, S. K., Xu, J., Shi, Q., Liu, H., et al. (2019). The distribution of tryptophan-dependent indole-3-acetic acid synthesis pathways in bacteria unraveled by large-scale genomic analysis. Molecules 24:1411. doi: 10.3390/ molecules 24071411
Conflict of Interest: The authors declare that the research was conducted in the absence of any commercial or financial relationships that could be construed as a potential conflict of interest.

Copyright (c) 2021 Kaur and Sharma. This is an open-access article distributed under the terms of the Creative Commons Attribution License (CC BY). The use, distribution or reproduction in other forums is permitted, provided the original author(s) and the copyright owner(s) are credited and that the original publication in this journal is cited, in accordance with accepted academic practice. No use, distribution or reproduction is permitted which does not comply with these terms. 